\title{
海生二枚貝類の貝殼を用いた成長線解析・酸素同位体比分析 一完新世環境変動の高分解能解析一
}

\author{
北 村 晃 寿 *
}

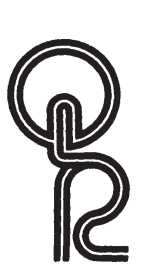

日本第四紀学会の組織改革で新たに設置される 5 領域のうち, 領域「人類と生物圈」では,「気 候・環境変動が人類と生物へ及ぼす影響, 人類と生物圈・環境の動的相互作用に関係する諸テー マ」を扱う。これらの中で, 本論では, 「気候・環境変動が人類と生物へ及ぼす影響」の解明の一 環として, 中・高緯度の完新世浅海環境の変動を高分解能で復元するのに有効な「海生二枚貝類 の貝殼の成長線解析・酸素同位体比分析」についてレビューする，そこで，まず，成長線解析・ 酸素同位体比分析の研究方法を概説する. その後, 研究事例として, とてつもなく長寿命の Arctica islandica, 浅海の二枚貝の Phacosoma japonicum, 海底洞窟生微小二枚貝の Carditella iejimensisの事例研究を紹介する.

キーワード : 海生二枚貝類, 貝殼, 成長線解析, 酸素同位体比分析, 完新世環境变動

\section{I. は じめに}

日本第四紀学会は, 2017 年度より, 第四紀学の研究 テーマに関連した 5 領域を設定し, 正会員はいずれかの 領域に所属する (会則第 15 条)。それに先立って, 2016 年大会シンポジウムでは, 5 領域の活動内容の紹介が企 画された.この中で, 著者は「領域 4 : 人類と生物圈」の 内容の一つとして, 大型無脊椎動物のうち化石産出頻度 の最も高い海生貝類を対象として, 第四紀環境変動に対 する生物地理的・進化学的応答について講演した. その 主な内容は次の通りである。

（1）第四紀の種分化と絶滅の速度はそれ以前の時代 と差はなく, 水期一間水期サイクルなどの環境変動に対 して種や個体群は, 移動によって対応した.

（2）未来予測に必須情報である生物種の「環境耐性の 保守性」の評価に，第四紀の化石記録が極めて有効であ る.

これらの内容は, 日本第四紀学会が出版した「デジタ ルブック最新第四紀学」において, 著者が執筆した「更新 世の貝化石」ですでに論述している. そこで, 本論では, シンポジウムと「更新世の貝化石」で扱っていない二枚 貝類の貝殼の成長線解析と酸素同位体比分析の研究事例
を紹介することとした．酸素同位体比分析技術の進展に よって, 様々な二枚貝種から数年〜数百年間の水温の季 節変動デー夕を入手できるようになり，完新世環境変動 の分析方法としての重要度は着実に上がり続けている.

\section{II. 研 究 方 法}

\section{1. 成長線解析}

成長線解析については, 大野 (1989) や佐藤 (2001) な どが概説している。 二枚貝類を含む軟体動物の貝款は, その縁辺部に, 新しい貝殼物質 (アラレ石・方解石) が付 加されることで成長する. 成長速度は, 誕生当初は遅く, 徐々に増加し, ある程度の大きさになり性成熟に達した 後は次第に遅くなり, 最終的にはある飽和点に近づいて 成長は停滞する，貝殼には様々なスケールの成長線が観 察される場合がある. 成長線は貝殼物質の付加の過程で 生じた生理的・物理的な不連続によって生じ, 肉眼でも 見える暗色層 (成長輪) と, 顕微鏡で確認できる程度の 微細な成長線 (微細成長縞)がある. 微細成長縞のうち, エッチングに対する抵抗力の強い細い層を微細成長線 (microgrowth line), 微細成長線の間の層を微細成長 輪 (microgorwth increment) と言う。そして微細成長 縞の付加パターンに不規則な乱れが見られる場合, これ

2017 年 3 月 22 日受付. 2017 年 9 月 15 日受理.

* 静岡大学大学院理学研究科 T422-8529 静岡市駿河区大谷 836. E-mail : kitamura.akihisa@shizuoka.ac.jp 
を成長障害輪 (growth break) といい, 冬期の低温や夏 期の高温, 突然の温度変化, 放精・放卵, 嵐による洗い 出し, などの様々な要因によって生じる (佐藤, 2010). 成長線解析では, 貝殼の最大成長軸に沿って切断・研 磨した断面で成長輪や微細成長縞を観察し, その際には 成長輪や成長障害輪の種類の識別が重要である。 そし て, 飼育 (例えば, Ohno, 1985), 標識個体の成長追跡 調査(例えば, Tanabe, 1988) あるいは貝殼の酸素同位 体比測定により，成長輪あるいは成長障害輪が 1 年に 1 本ずつ形成されることが確認された種では，それらを年 輪として個体の年齢查定や絶対成長の解析や採集期の推 定 (Koike, 1973 など) が可能となる. 但し, 研究対象 の個体についてはそれぞれの成長輪や微細成長縞の観察 は不可欠である.

これらの成長輪や微細成長縞の形態的な見やすさは, 種によって異なり, カガミガイ (Phacosoma japonicum) やアイスランドガイ (Arctica islandica) のような明暸 な種もいるが, 不明瞭な種もいる. 例えば, 著者らが 扱ったイエジマケシザルガイ (Carditella iejimensis) やツキヨミガイ (Glossocardia obesa) は不明瞭である (Yamamoto et al., 2009 ; Kitamura et al., 2011). なお, Mutvei 溶液によるエッチングと染色法を用いると, 種 によっては微細成長縞がより明膫になり, 観察しやすく なる (Mutvei et al., 1994).

\section{2. 酸素同位体比}

成長線解析と酸素同位体比分析を組み合わせることに より, 海生二枚貝類の貝殼から, 年間〜数週間スケール の環境情報を連続的に入手できる点で, 有孔虫殼のデー 夕と異なる. 海生二枚貝類の貝殼の酸素同位体比分析は 世界各地で盛んに行われており, 表 1 に, 日本列島周辺 に生息する種を中心に, 研究事例の一部を示した. なお, 我が国において，貝殼成長線と酸素同位体測定が体系的 に行われた最初の例は, Chinzei et al. (1987) である.

二枚貝類の貝殼はアラレ石あるいは方解石からなる. 無機沈殿させたアラレ石と方解石の酸素同位体比か ら, 温度と海水の酸素同位体比の関係式は得られている (O’Neil et al., 1969 ; Kim and O’Neil, 1997 ; Kim et al., 2007). しかし, 貝殼の酸素同位体比と温度の関係式 は, 無機沈殿のものから得られた関係式からわずかにず れている(例えば, Kim et al., 2007). したがって, 研究 対象種の水温換算式を検討することが望ましい(表 2).

Ishimura et al. (2004, 2008) は微量炭酸塩安定同位 体組成定量システムを開発した。 このシステムを使うと $0.2 \mu \mathrm{g}$ (マイクロインレットシステムなどの従来法の
$1 / 100$ 以下) の試料を高精度 $\left(\delta^{18} \mathrm{O}\right.$ の外部精度は $0.2 \%$ 以下) で分析できるようになった．また, Sakai (2006) は試料から $1 \mu \mathrm{m}$ 単位の精度で分析試料を削り出す高精 度マイクロミルシステムを開発した．これらの技術革新 によって, 従来よりも微小な部分の測定が可能となり, 例えば，性成熟後の成長速度が鈍化した部分からも高分 解能のデータが得られるようになった。

\section{III. 研 究 事 例}

二枚貝類の貝殼の成長線解析と酸素同位体比分析の研 究事例として, 本論では, 以下の 3 種を紹介する. Arctica islandica (アイスランドガイ) と Phacosoma japonicum (カガミガイ) は, 貝殼サイズが数 $\mathrm{cm}$ なので, 研究方法 は共通する. Carditella iejimensis（イエジマケシザル ガイ) は微小二枚貝であり, 上記 2 種とは研究方法が異 なる.

\section{Arctica islandica}

本種は北大西洋の浅海に生息し, 殼長は約 $10 \mathrm{~cm}$ であ る. Abbott and Dance (1981) によると 10〜 $160 \mathrm{~m}$ の 海域から採取される. 貝殼成長の下限水温は $5 \sim 6{ }^{\circ} \mathrm{C}$ で ある (Weidman et al., 1994 ; Schöne et al., 2005a). 最 も寿命の個体は 507 年で, これは動物の中で最長寿命の 個体である (Wanamaker et al., 2012)。本種は性成熟 後も死ぬまで成長続ける。 これらの生活史に関する知見 は貝殼の成長線解析と ${ }^{14} \mathrm{C}$ 年代測定によって得られたも のである.

Schöne et al. (2005b) は 1868 年 7 月にアイスランド 近海から生きたまま採取された 1 個体 (374 齢) の成長 線解析を行い, 2 40 齢の部分 (西暦 1496〜1533 年に 対応）の酸素同位体比を測定した，その結果，貝殼成長 の年変動量の $65 \%$ は夏の水温と餌の供給量で説明でき, 成長量が極端に小さい部分は大規模な火山噴火 (例え ば, 1815 年の夕ンボラ火山の噴火) と一致することが 判明した．また，年成長量が大きく変動する期間は西暦 1550 1620 年の小水期最盛期に起きた。一方, 西暦 $1765 \sim 1780$ 年の成長は年ごとの変動が小さく, 小水期末 期のかなり穏やかな気候だったことの結果と解釈した. 酸素同位体比から推定した西暦 1496〜1533 年の水温は $4.5 \sim 9.3^{\circ} \mathrm{C}$ の間で変動し, 平均水温は $6.2^{\circ} \mathrm{C}$ である. こ の平均水温は 1854 2003 年の 2 9 月 (A. islandica の 成長期間) の海洋表層水温の平均值 $6.81^{\circ} \mathrm{C}$ と一致する.

Wanamaker et al. (2008) は北アイスランドの陸棚の 深度 81 83 m から A. islandica の生貝, 合弁死款, 離 弁死殼の貝殼を採取し (Cruise No. B05-2006)，それら 
表 1 日本列島周辺および北半球中緯度などに生息する二枚貝種を中心とした酸素同位体比分析の研究事例

\begin{tabular}{|c|c|c|c|}
\hline 種 & 鉱物種 & 分布 & 主な研究事例 \\
\hline Scapharca broughtonii & $\mathrm{A}(\mathrm{I}+\mathrm{O})$ & $\mathrm{J}$ & Nishida et al . (2012) \\
\hline Limopsis belcheli & $\mathrm{A}(\mathrm{I}+\mathrm{O})$ & $\mathrm{J}$ & 青島・鎮西 (1972) \\
\hline Glycymeris fulgurata & $\mathrm{A}(\mathrm{I}+\mathrm{O})$ & $\mathrm{J}$ & Yamaoka et al. (2016) \\
\hline Glycymeris vestita & $\mathrm{A}(\mathrm{I}+\mathrm{O})$ & $\mathrm{J}$ & Yamaoka et al.(2016) \\
\hline Glycymeris yessoensis & $\mathrm{A}(\mathrm{I}+\mathrm{O})$ & $\mathrm{J}$ & 菅野ほか (1972) \\
\hline Mytilus californianus & $\mathrm{C}(\mathrm{O}), \mathrm{A}(\mathrm{I})$ & $\mathrm{EP}$ & Ford et al . (2010) \\
\hline Mytilus edulis & $\mathrm{C}(\mathrm{O}), \mathrm{A}(\mathrm{I})$ & $\mathrm{J}$ & Wanamaker et al. (2007) \\
\hline Pinna nobilis & $\mathrm{C}(\mathrm{O}), \mathrm{A}(\mathrm{I})$ & M & Kennedy et al. (2001) \\
\hline Aequipecten opercularis & $\mathrm{C}(\mathrm{I}+\mathrm{O})$ & NA & Hickson et al. (1999) \\
\hline Pecten maximus & $\mathrm{C}(\mathrm{I}+\mathrm{O})$ & NA & Chauvaud et al. (2005), Owen et al. (2002) \\
\hline Comptopallium radula & $\mathrm{C}(\mathrm{I}+\mathrm{O})$ & $\mathrm{P}$ & Thébault et al . (2007) \\
\hline Spondylus gaederopus & $\mathrm{C}(\mathrm{I}+\mathrm{O})$ & M & Maier and Titschack (2010) \\
\hline Hyotissa hyotis & $\mathrm{C}(\mathrm{I}+\mathrm{O})$ & $\mathrm{P} \& \mathrm{~A}$ & Titschack et al . (2010) \\
\hline Crassostrea gigas & $\mathrm{C}(\mathrm{I}+\mathrm{O})$ & $\mathrm{J}$ & Fan et al. (2011), Ullmann et al . (2010) \\
\hline Carditella iejimensis & $\mathrm{A}(\mathrm{I}+\mathrm{O})$ & $\mathrm{J}$ & $\begin{array}{l}\text { Kitamura et al. (2007, 2012, 2013), Yamamoto et al . (2009, } \\
2010)\end{array}$ \\
\hline Astarte borealis & $\mathrm{A}(\mathrm{I}+\mathrm{O})$ & $\mathrm{J}$ & Khim et al . (2001), Mcnabb (2014) \\
\hline Serripes groenlandicus & $\mathrm{A}(\mathrm{I}+\mathrm{O})$ & $\mathrm{J}$ & Khim et al. (2001) \\
\hline Tridacna derasa & $\mathrm{A}(\mathrm{I}+\mathrm{O})$ & $\mathrm{J}$ & Yamanashi et al. (2016) \\
\hline Tridacna gigas & $\mathrm{A}(\mathrm{I}+\mathrm{O})$ & $\mathrm{J}$ & $\begin{array}{l}\text { Aharon (1983), Jones et al . (1986), Watanabe et al . (2004), } \\
\text { Welsh et al . (2011) }\end{array}$ \\
\hline Hippopus hippopus & $\mathrm{A}(\mathrm{I}+\mathrm{O})$ & $\mathrm{J}$ & Aubert et al. (2009), Watanabe and Oba (1999) \\
\hline Mactra chinensis & $\mathrm{A}(\mathrm{I}+\mathrm{O})$ & $\mathrm{J}$ & Khim et al. (2001) \\
\hline Spisula sachalinensis & $\mathrm{A}(\mathrm{I}+\mathrm{O})$ & $\mathrm{J}$ & Khim et al. (2001) \\
\hline Spisula solidissima & $\mathrm{A}(\mathrm{I}+\mathrm{O})$ & ENP & Jones et al. (1983) \\
\hline Mesodesma donacium & $\mathrm{A}(\mathrm{I}+\mathrm{O})$ & ESP & Carré et al. (2005) \\
\hline Macoma calcarea & $\mathrm{A}(\mathrm{I}+\mathrm{O})$ & $\mathrm{J}$ & Khim et al. (2001) \\
\hline Donax variabilis & $\mathrm{A}(\mathrm{I}+\mathrm{O})$ & A & Jones et al. (2005) \\
\hline Scrobicularia plana & $\mathrm{A}(\mathrm{I}+\mathrm{O})$ & A & Santos et al. (2012) \\
\hline Arctica islandica & $\mathrm{A}(\mathrm{I}+\mathrm{O})$ & A & $\begin{array}{l}\text { Butler et al. (2013), Reynolds et al. (2016), Schöne et al. } \\
\text { (2005a, b), Wanamaker et al . (2008, 2012), Weidman et al . } \\
\text { (1994) }\end{array}$ \\
\hline Glossocardia obesa & $\mathrm{A}(\mathrm{I}+\mathrm{O})$ & $\mathrm{J}$ & Kitamura et al . (2007) \\
\hline Saxidomus giganteus & $\mathrm{A}(\mathrm{I}+\mathrm{O})$ & ENP & Gillikin et al. (2005) \\
\hline Phacosoma japonicum & $\mathrm{A}(\mathrm{I}+\mathrm{O})$ & $\mathrm{J}$ & $\begin{array}{l}\text { Miyaji et al . }(2007,2010) \text {, Schöne et al . (2003), Tanabe and } \\
\text { Oba (1988) }\end{array}$ \\
\hline Meretrix lamarckii & $\mathrm{A}(\mathrm{I}+\mathrm{O})$ & $\mathrm{J}$ & Koike (1973), Chinzei et al . (1987) \\
\hline Ruditapes philippinarum & $\mathrm{A}(\mathrm{I}+\mathrm{O})$ & $\mathrm{J}$ & 富岡ほか(2015) \\
\hline Chione californiensis & $\mathrm{A}(\mathrm{I}+\mathrm{O})$ & EP & Goodwin et al. (2001) \\
\hline Chione cortezi & $\mathrm{A}(\mathrm{I}+\mathrm{O})$ & $\mathrm{EP} \& \mathrm{C}$ & Goodwin et al. (2001, 2003), Schöne et al . (2002) \\
\hline Mercenaria campechiensis & $\mathrm{A}(\mathrm{I}+\mathrm{O})$ & A & Surge and Walker (2006) \\
\hline Mercenaria mercenaria & $\mathrm{A}(\mathrm{I}+\mathrm{O})$ & A & $\begin{array}{l}\text { Peterson et al . (1983), Jones et al . (1989), Elliot et al . (2003), } \\
\text { Gillikin et al. (2005) }\end{array}$ \\
\hline Mercenaria stimpsoni & $\mathrm{A}(\mathrm{I}+\mathrm{O})$ & $\mathrm{J}$ & Kubota et al. (2017) \\
\hline Protothaca staminea & $\mathrm{A}(\mathrm{I}+\mathrm{O})$ & $\mathrm{EP}$ & Takesue and van Geen (2004) \\
\hline Mya japonica & $\mathrm{A}(\mathrm{I}+\mathrm{O})$ & $\mathrm{J}$ & Khim et al. (2001) \\
\hline Hiatella arctica & $\mathrm{A}(\mathrm{I}+\mathrm{O})$ & $\mathrm{J}$ & Khim et al. (2001) \\
\hline Panopea abrupta & $\mathrm{A}(\mathrm{I}+\mathrm{O})$ & $\mathrm{P}$ & Goman et al. (2008) \\
\hline
\end{tabular}

鉱物種の $\mathrm{A}, \mathrm{C}$ はそれぞれアラレ石と方解石である。 I, O はそれぞれ内層と外層である。分布の略号は， A は大西洋, C はカリブ海, EP は東太平洋, ENP は北東太平洋, ESP は南東太平洋, J は日本周辺海域, M は 地中海, NA は北大西洋, P は太平洋. 学名と地理分布は Abbott and Dance (1981) と奥谷 (2000) に基づく. 
表 2 アラレ石㧍よび方解石の酸素同位体比と水温の関倸式

Aragonite

\begin{tabular}{ll}
\hline $10^{3} \ln \alpha_{\text {aragonite-water }}=17.88 \pm 0.13\left(10^{3} / K\right)-31.14 \pm 0.46$ for inorganic aragonite & Kim et al . (2007) \\
\hline $\begin{array}{l}T=13.85-4.54\left(\delta^{18} \mathrm{O}_{\text {calcite }}-\delta^{18} \mathrm{O}_{\text {water }}\right)+0.04\left(\delta^{18} \mathrm{O}_{\text {calcite }}-\delta^{18} \mathrm{O}_{\text {water }}\right)^{2} \\
\text { for Scapharca broughtonii }\end{array}$ & 堀部 • 大場 (1972) \\
\hline$T=19.02-3.73\left(\delta^{18} \mathrm{O}_{\text {aragonite }}-\delta^{18} \mathrm{O}_{\text {water }}\right)$ & Dunbar and Wefer (1984) \\
\hline$T=20.6-4.34\left\{\delta^{18} \mathrm{O}_{\text {aragonite }}-\left(\delta^{18} \mathrm{O}_{\text {water }}-0.2\right)\right\}$ & Grossman and Ku (1986) \\
\hline$T=17.23-4.47\left(\delta^{18} \mathrm{O}_{\text {aragonite }}-\delta^{18} \mathrm{O}_{\text {water }}\right)$ & Patterson et al . (1993) \\
\hline $10^{3} \ln \alpha_{\text {aragonite-water }}=18.56\left(10^{3} / K\right)-33.49$ & Thorrold et al . (1997) \\
\hline $10^{3} \ln \alpha_{\text {aragonite-water }}=18.56\left(10^{3} / K\right)-32.54$ & Carré et al . (2005) \\
\hline$T=(17.41 \pm 1.15)-(3.66 \pm 0.16)\left(\delta^{18} \mathrm{O}_{\text {aragonite }}-\delta^{18} \mathrm{O}_{\text {water }}\right)$ & Aubert et al . (2009) \\
for Mesodesma donacium & \\
\hline$T=21.4-2.87\left(\delta^{18} \mathrm{O}_{\text {aragonite }}-\delta^{18} \mathrm{O}_{\text {water }}\right)$ & \\
for Hippopus hippopus &
\end{tabular}

Calcite

\begin{tabular}{|c|c|}
\hline$T=16.9-4.38\left(\delta^{18} \mathrm{O}_{\text {calcite }}-\delta^{18} \mathrm{O}_{\text {water }}\right)+0.10\left(\delta^{18} \mathrm{O}_{\text {calcite }}-\delta^{18} \mathrm{O}_{\text {water }}\right)^{2}$ & O'Neil et al.(1969) \\
\hline $\begin{array}{l}T=17.04-4.34\left(\delta^{18} \mathrm{O}_{\text {calcite }}-\delta^{18} \mathrm{O}_{\text {water }}\right)+0.16\left(\delta^{18} \mathrm{O}_{\text {calcite }}-\delta^{18} \mathrm{O}_{\text {water }}\right)^{2} \\
\text { for Patinopecten yessoensis }\end{array}$ & 堀部・大場 (1972) \\
\hline$T=16-4.14\left(\delta^{18} \mathrm{O}_{\text {calcite }}-\delta^{18} \mathrm{O}_{\text {water }}\right)+0.13\left(\delta^{18} \mathrm{O}_{\text {calcite }}-\delta^{18} \mathrm{O}_{\text {water }}\right)^{2}$ & Anderson and Arthur (1983) \\
\hline $\begin{array}{l}T=20.00( \pm 0.61)-3.66( \pm 0.39) \cdot\left(\delta^{18} \mathrm{O}_{\text {calcite }}-\delta^{18} \mathrm{O}_{\text {water }}\right) \\
\text { for Comptopallium radula }\end{array}$ & Thébault et al . (2007) \\
\hline $\begin{array}{l}10^{3} \ln \alpha_{\text {calcite-water }}=18.734 \pm 0.564\left(10^{3} / \mathrm{T}\right)-33.776 \pm 1.941 \\
\text { for Mytilus edulis }\end{array}$ & Wanamaker et al. (2007) \\
\hline $10^{3} \ln \alpha_{\text {calcite-water }}=18.03\left(10^{3} / K\right)-32.42$ & Kim and O'Neil (1997) \\
\hline
\end{tabular}

のうちの 2 試料について成長線解析と ${ }^{14} \mathrm{C}$ 測定を行い, ローカルリザーバー効果 $(\Delta \mathrm{R})$ の值が西暦 1600 年では $237 \pm 35$ 年, 西暦 1650 年では $186 \pm 50$ 年であることを 明らかにした. さらにWanamaker et al. (2012) は同 航海で採取された 24 個の貝殼を分析し，これらの個体 の成長線パターンへ年輪年代学的手法を適用し，個体間 の対比を行い, 西暦 649 年までの 1357 年間の $\Delta \mathrm{R}$ 值を 算出した. この $\Delta \mathrm{R}$ 值は, 正の場合は北極海起源の水塊 の影響の増大を，負の場合には大西洋起源の表層水の影 響の増大を示す. そして, Wanamaker et al. (2012) は $\Delta \mathrm{R}$ 值の変動から, 大西洋表層の子午面循環が中世温暖 期や小水期の気候変動を増幅したと推定している. な お，この分析時に，507 齢という世界最長寿の個体を見 つけた.

この Wanamaker et al. (2012) の試料について, Butler et al. (2013) は年間成長速度を測定し, その結果から 1,000 年間の水温変化を推定した. さらに, Reynolds et al. (2016) は Wanamaker et al. (2012)の試料に関し て酸素同位体比測定を行い, 西暦 953～2000 年までの 毎年の同位体比データを得た。 そして, 産業革命前の西 暦 1000 1800 年の間では，数十年スケールの変動に関 しては, 北大西洋覀北極の変動は北半球表層気温の変動 よりも先行することを明らかにした。 このように 1,000 年にも及ぶ連続データが得られたのは, ひとえに $A$. islandicaの驚愕すべき長寿命に依存し, 本種を二枚具 のメトシュラ (Methuselah) と表現した論文もある (Schöne et al., 2005b).

\section{Phacosoma japonicum}

日本を含む北太平洋域で最も成長線解析・酸素同位体 比分析されている二枚具はP. japonicum である. 本種 
の成長線解析は, Tanabe (1988) による瀬戸内海の干 潟に打ける成長追跡調査から始まる。 さらに, Tanabe and Oba (1988) は稚内, 函館湾, 東京湾, 瀬戸内海, 有明海の個体群の成長線解析と酸素同位体比測定を行 い, (1) 冬期に形成される成長障害輪によって年間付加 量の推定が可能であること，(2) 南方の個体ほど微細成 長縞の数は増大し, 一方, 微細成長縞の平均の厚さは減 少すること，(3) 成長期間は䭒の植物プランクトンの多 い季節であること, を明らかにした。

Sato（1995）は，放精・放卵と冬期低温による成長障 害輪の識別方法を検討した. その結果, 放精・放卵の成 長障害輪 (放精・放卵輪) は最も微細成長縞の幅の広い 夏季に突然幅の狭い微細成長縞が付加して形成されるの に対して, 冬期低温による成長障害輪 (冬輪) は微細成 長縞の幅が次第に狭くなり, 冬輪の付加後, 徐々に幅が 回復する付加パターンを示すことを明らかにした。ま た, 冬輪は V 字型の切れ込みを伴うため, 殼表面から も容易に識別できることを明らかにした。

Miyaji et al. (2007) は, (1) 微細成長縞は 1 朔望日 (24 時間 50 分) ごとに形成され, その幅の変動パター ンは潮汐周期を反映していること，(2) 成長に関与する 主な環境因子は表層海水温 (成長最適水温は $21 \sim 24^{\circ} \mathrm{C}$ ) だが，塩分や飭となる植物プランクトン量も寄与してい る，ことを明らかにした。

これらの基礎研究を基に, Schöne et al. (2004)や Miyaji et al. (2010) は, 日本列島各地の完新統や貝塚 などから採取された化石個体の成長線解析と酸素同位体 比測定を行い, 過去 7,000 年間の東京湾周辺産の化石 貝殼の年間成長日数, 日平均成長量, 朔望日輪の年間付 加パターンが気候変動に応答して変化したことを明らか にした。

Phacosoma japonicum は基礎研究が十分に行われて いるが，A. islandicaのように個体と個体を対比するこ とで，1個体の寿命を超えた期間の連続記録をコンパイ ルできるほどの数の個体を入手できた例はない. 例えば, 前述の Miyaji et al. (2010) の解析した試料のうち最も 新しい個体は $470 \pm 30$ 年前で, 最も古い個体は 6,820 \pm 70 年前であるが，その間の試料数はわずか 14 個体で ある.したがって, P. japonicumでは A. islandicaの ように重複する成長期間を繋いで複数個体の記録を連結 することは不可能である. また, P. japonicum の主な 生息場所である内湾の潮間帯は河川水の影響を受けるう え, 河口の位置変化などの局地的な地形変化によって水 質が変わりうる点も酸素同位体比の解釈を難しくする.
したがって，P.japonicum は，完新世浅海環境の長期 的記録媒体よりも, むしろ個体の生理状態が微細成長線 パターンに反映する点が特徴であり, 生活史の解析に最 適の素材と言える.

\section{Carditella iejimensis}

上記二種で明らかなように, “短寿命”の二枚貝から環 境情報の連続記録を得るには, 多産する種が適してい る.このような観点で, サンゴ礁斜面の海底洞窟に多産 する微小二枚貝 C. iejimensis は最適である. その理由 は, (1) 海底洞窟は波浪から遮蔽されているため, 堆積 物が連続的に堆積していること (北村ほか, 2003), (2) 海底洞窟は貧栄養のため, 大型動物による堆積物の擋拌 が少ないので, 化石記録の時間的平均化は 100 300 年 程度と低いこと（Kitamura et al., 2007)，（3）礁斜面は 地形的変化が云しいので, 内湾干潟に比べると環境は長 期的に不変であること, (4) 洞窟内に生息場が限定され ているので死殼は現地性である (同一深度のアーカイ ブ)こと,である.

Carditella iejimensis は最大殼長 $4 \mathrm{~mm}$ で, 堆積物表 面に生息し, 殼は $100 \%$ アラレ石である. 貝殼は外層と 内層に分かれ，成長線は不明暸である (Yamamoto et al., 2009). Kitamura et al. (2012) は標識個体の殼成長追跡 調査を行い, 1 年を通じて殼成長を行う可能性が高いこ と, 殸長 $3 \mathrm{~mm}$ に達するまでに, 少なくとも 4 年間を要 するものと推定した. さらに, Kitamura et al. (2013) は, 生貝の酸素同位体比と大洞窟の水温とを直接比較 し，同殼の酸素同位体比が大洞窟の水温ならびに海水の 酸素同位体比の変化をよく反映していることを明らかに した.この結果を踏まえて, Kitamura et al. (2013) は, Yamamoto et al. (2010) がコア堆積物から抽出した右殼 86 個，左殼 74 個の全殼の酸素同位体比の記録を再評価 し, (1) 6,300 年前と 5,550 年前は海水の酸素同位体比 が重くなった時期があったこと, (2) 過去 7,000 年間で, 近年が例外的に温暖な状況にあること，を示した。

著者は, 微小二枚貝の C. iejimensis の外層から微量 試料を抽出し, 酸素同位体比測定を行い, 季節スケール で環境変動を解析する予定だったが，2011 年 3 月 11 日 の東北日本太平洋沖地震とそれに伴う巨大津波の発生後 に, 静岡県内の古地震・古津波の研究にシフトしたた め, その研究は中断している.

\section{IV. おわりに}

日本周辺には海洋生物地理区の境界が位置し，国民へ の供給総たんぱく質の 2 割が魚介類である.こうした状 
況を鑑みると, 日本周辺の海洋環境変化と海洋生態系の 動向予測は重要な研究課題である. この研究課題の遂行 にも, 海生二枚貝類の貝殼の成長線解析・酸素同位体比 分析による完新世の環境変動の高精度解析は重要な役割 を果たすと期待される.

\section{引用文 献}

Abbott, R.T. and Dance, S.P. (1981) Compendium of seashells. 411 p, Madison Publishing Associates.

Aharon, P. (1983) 140,000-year isotope climatic record from raised coral reefs in New Guinea. Nature, 304, 720-723.

Anderson, T.F. and Arthur, M.A. (1983) Stable isotopes of oxygen and carbon and their application to sedimentologic and paleoenvironmental problems. Stable Isotopes in Sedimentary Geology, SEPM Short Course, 10, 1-1 to 1-155.

青島睦治・鏡西清高（1972）化石硬組織の酸素同位体 比に基づく掛川層群堆積時の古水温推定. 化石, 23 24, 80-91.

Aubert, A., Lazareth, C., Cabioch, G., Boucher, H., Yamada, T., Iryu, Y. and Farman, R. (2009) The tropical giant clam Hippopus hippopus shell, a new archive of environmental conditions as revealed by sclerochronological and $\delta^{18} \mathrm{O}$ profiles. Coral Reefs, 28, 989-998.

Butler, P.G., Wanamaker, A.D., Scourse, J.D., Richardson, C.A. and Reynolds, D.J. (2013) Variability of marine climate on the North Icelandic Shelf in a 1357-year proxy archive based on growth increments in the bivalve Arctica islandica. Palaeogeography, Palaeoclimatology, Palaeoecology, 373, 141-151.

Carré, M., Bentaleb, I., Blamart, D., Ogle, N., Cardenas, F., Zevallos, S., Kalin, R.M., Ortlieb, L. and Fontugne, M. (2005) Stable isotopes and sclerochronology of the bivalve Mesodesma donacium : potential application to Peruvian paleoceanographic reconstructions. Palaeogeography, Palaeoclimatology, Palaeoecology, 228, 4-25.

Chauvaud, L., Lorrain, A., Dunbar, R.B., Paulet, Y.-M., Thouzeau, G., Jean, F., Guarini, J.-M. and Mucciarone, D. (2005) Shell of the great scallop Pecten maximus as a high-frequency archive of paleoenvironmental changes. Geochemistry Geophysics Geosystems 6, Q08001, doi:10.1029/2004GC000890.

Chinzei, K., Koike, H., Oba, T., Matsushima, Y. and Kitazato, H. (1987) Secular changes in the oxygen isotope ratios of mollusc shells during the Holocene of central Japan. Palaeogeography, Palaeoclimatology, Palaeoecology, 61, 155-166.

Dunbar, R.B. and Wefer, G. (1984) Stable isotope fractionation in benthic foraminifera from Peruvian continental margin. Marine Geology, 59, 215-225.

Elliot, M., deMenocal, P.B., Linsley, B.K. and Howeand, S.S. (2003) Environmental controls on the stable isotopic composition of Mercenaria mercenaria : Potential application to paleoenvironmental studies. Geochemistry, Geophysics, Geosystems, 4, 1056, doi: 10.1029/2002GC000425.

Fan, C., Koeniger, P., Wang, H. and Frechen, M. (2011) Ligamental increments of the mid-Holocene Pacific oyster Crassostrea gigas are reliable independent proxies for seasonality in the western Bohai Sea, China. Palaeogeography, Palaeoclimatology, Palaeoecology, 299, 437-448.

Ford, H.L., Schellenberg, S.A., Becker, B.J., Deutschman, D.L., Dyck, K.A. and Koch, P.L. (2010) Evaluating the skeletal chemistry of Mytilus californianus as a temperature proxy : Effects of microenvironment and ontogeny. Paleoceanography, 25, doi:10.1029/ 2008PA001677.

Gillikin, D.P., Lorrain, A., Naves, J., Taylor, J.W., André, L., Keppens, E., Baeyens, W. and Dehairs, F. (2005) Strong biological controls on Sr/Ca rations in aragonitic marine bivalve shells. Geochemistry, Geophysics, Geosystems, 6, 1-16.

Goman, M., Ingram, B.L. and Strom, A. (2008) Composition of stable isotopes in geoduck (Panopea abrupta) shells : a preliminary assessment of annual and seasonal paleoceanographic changes in the northeast Pacific. Quaternary International, 188, 117-125.

Goodwin, D.H., Flessa, K.W., Schöne, B.R. and Dettman, D.L. (2001) Cross-calibration of daily growth increments, stable isotope variations, and temperature in the Gulf of California bivalve mollusk Chione cortezi : implications for paleoenvironmental 
analysis. Palaios, 16, 387-398.

Goodwin, D.H., Schöne, B.R. and Dettman, D.L. (2003) Resolution and fidelity of oxygen isotopes as paleotemperature proxies in bivalve mollusk shells: models and observations. Palaios, 18, 110125.

Grossman, E. and Ku, T. (1986) Oxygen and carbon isotope fractionation in biogenic aragonite : temperature effects. Chemical Geology, 59, 59-74.

Hickson, J.A., Johnson, A.L.A., Heaton, T.H.E. and Balson, P.S. (1999) The shell of the Queen Scallop Aequipecten opercularis (L.) as a promising tool for palaeoenvironmental reconstruction : Evidence and reasons for equilibrium stable-isotope incorporation. Palaeogeography, Palaeoclimatology, Palaeoecology, 154, 325-337.

堀部純男 ・ 大場忠道 (1972) アラレ石一水および方解 石一水系の温度スケール．化石, $23 \cdot 24,69-79$.

Ishimura, T., Tsunogai, U. and Gamo, T. (2004) Stable carbon and oxygen isotopic determination of submicrogram quantities of $\mathrm{CaCO}_{3}$ to analyze individual foraminiferal shells. Rapid communications in mass spectrometry : RCM, 18, 2883-2888.

Ishimura, T., Tsunogai, U. and Nakagawa, F. (2008) Grain-scale heterogeneities in the stable carbon and oxygen isotopic compositions of the international standard calcite materials (NBS 19, NBS 18, IAEA-CO-1, and IAEA-CO-8). Rapid communications in mass spectrometry : RCM, 22, 19251932.

Jones, D.S., Williams, D.F. and Arthur, M.A. (1983) Growth history and ecology of the Atlantic surf clam Spisula solidissima (Dillwyn) as revealed by stable isotopes and annual growth increments. Journal of Experimental Marine Biology and Ecology, 73, 225-242.

Jones, D.S., Williams, D.F. and Romanek, C.S. (1986) Life history of symbiont-bearing giant clams from stable isotope profiles. Science, 231, 46-48.

Jones, D.S., Arthur, M.A. and Allard, D.J. (1989) Sclerochronological records of temperature and growth from of Mercenaria mercenaria from Narragansett Bay, Rhode Island. Marine Biology, 102, 225-234.
Jones, D.S., Quitmyer, I.R. and Andrus, C.F.T. (2005) Oxygen isotopic evidence for greater seasonality in Holocene shells of Donax variabilis from Florida. Palaeogeography, Palaeoclimatology, Palaeoecology, 228, 96-108.

菅野三郎・平 一弘・増田富士雄（1972）酸素同位体 比からみた “成田層群” 産貝化石の古水温とその古生 物学的検討. 化石, $23 \cdot 24,92-107$.

Kennedy, H., Richardson, C.A., Duarte, C.M. and Kennedy, D.P. (2001) Oxygen and carbon stable isotope profiles of the fan mussel Pinna nobilis, and reconstruction of sea surface temperatures in the Mediterranean. Marine Biology, 139, 11151124.

Khim, B.K., Krantz, D.E. and Brigham-Grette, J. (2001) Stable isotope profiles of Last Interglacial (Pelukian Transgression) mollusks and paleoclimate implications in the Bering Strait region. Quaternary Science Reviews, 20, 463-483.

Kim, S.T. and O’Neil, J.R. (1997) Equilibrium and nonequilibrium oxygen isotope effects in synthetic carbonates. Geochimica et Cosmochimica Acta, 61, 3461-3475.

Kim, S.-T., O’Neil, J.R., Hillaire-Marcel, C. and Mucci, A. (2007) Oxygen isotope fractionation between synthetic aragonite and water : Influence of temperature and $\mathrm{Mg}^{2+}$ concentration. Geochimica et Cosmochimica Acta, 71, 4704-4715.

北村晃寿 - 加瀬友喜 - 大橋秀一 - 平本真弓 - 坂口佳孝 . 田辺晶史・間藤基之（2003）沖縄のサンゴ礁にある海 底洞窟堆積物の堆積相と堆積速度. 第四紀研究, 42 , 99-104.

Kitamura, A., Yamamoto, N., Kase, T., Ohashi, S., Hiramoto, M., Fukusawa, H., Watanabe, T., Irino, T., Kojitani, H., Shimamura, M. and Kawakami, I. (2007) Potential of submarine-cave sediments and oxygen isotope composition of cavernicolous micro-bivalve as a late Holocene paleoenvironmental record. Global and Planetary Change, 55, 301-316.

Kitamura, A., Tada, K., Sakai, S., Yamamoto, N., Ubukata, T., Miyaji, T. and Kase, T. (2011) Age and growth of Glossocardia obesa, a "large" bivalve in a submarine cave within a coral reef, as revealed by oxygen isotope analysis. The Veliger, 51, 59- 
65.

Kitamura, A., Yamamoto, N. and Kobayashi, K. (2012) Growth of a submarine cave-dwelling micro-bivalve Carditella iejimensis. Venus, 70, 41-45.

Kitamura, A., Kobayashi, K., Tamaki, C., Yamamoto, N., Irino, T., Miyairi, Y. and Yokoyama, Y. (2013) Evidence of recent warming in the Okinawa region, subtropical northwestern Pacific, from an oxygen isotope record of a cave-dwelling marine microbivalve. Paleontological Research, 17, 58-68.

Koike, H. (1973) Daily growth lines of the clam, Meretrix lusoria-A basic study for the estimation of prehistoric seasonal gathering. Journal of the Anthropological Society of Nippon, 81, 122-138.

Kubota, K., Shirai, K., Murakami-Sugihara, N., Seike, K., Hori, M. and Tanabe, K. (2017) Annual shell growth pattern of the Stimpson's hard clam Mercenaria stimpsoni as revealed by sclerochronological and oxygen stable isotope measurements. Palaeogeography, Palaeoclimatology, Palaeoecology, 465, 307315.

Maier, E. and Titschack, J. (2010) Spondylus gaederopus : A new Mediterranean climate archive-Based on high-resolution oxygen and carbon isotope analyses. Palaeogeography Palaeoclimatology Palaeoecology, 291, 228-238.

Mcnabb, J.J. (2014) Establishing the lifespan of Astarte borealis (bivalvia) using isotope sclerochronology. GSA Annual Meeting in Vancouver, British Columbia, Paper No. 43-12.

Miyaji, T., Tanabe, K. and Schöne, B.R. (2007) Environmental controls on daily shell growth of Phacosoma japonicum (Bivalvia : Veneridae) from Japan. Marine Ecology Progress Series, 336, 141150.

Miyaji, T., Tanabe, K., Matsushima, Y., Sato, S., Yokoyama, Y. and Matsuzaki, H. (2010) Response of daily and annual shell growth patterns of the intertidal bivalve Phacosoma japonicum to Holocene coastal climate change in Japan. Palaeogeography, Palaeoclimatology, Palaeoecology, 286, 107-120.

Mutvei, H., Westermark, T., Dunca, E., Carell, B., Forsberg, S. and Bignert, A. (1994) Methods for the study of environmental changes using the structural and chemical information in molluscan shells. Past and present biomineralization processes : considerations about the carbonate cycle, Bulletin du Muse Océanographique de Monaco, Numéro Spécial, 13, 163-191.

Nishida, K., Ishimura, T., Suzuki, A. and Sasaki, T. (2012) Seasonal changes in the shell microstructure of the bloody clam, Scapharca broughtonii (Mollusca : Bivalvia: Arcidae). Palaeogeography, Palaeoclimatology, Palaeoecology, 363-364, 99-108.

Ohno, T. (1985) Experimentelle Analysen zur Rhythmik des Schalenwachstums einiger Bivalven und ihre palaeobiologische Bedeutung. Palaeontographica. 189, 62-123.

大野照文 (1989) 二枚貝の微細成長縞形成時間間隔の 多様性. 日本ベントス研究会誌, 37, 35-48.

奥谷喬司 (2000) 日本近海産貝類図鑑. $1173 \mathrm{p}$, 東海 大学出版会.

O’Neil, J.R., Clayton, R.N. and Mayeda, T.K. (1969) Oxygen isotope fractionation in divalent metal carbonates. Journal of Chemical Physics, 51, 55475558.

Owen, R., Kennedy, H. and Richardson, C. (2002) Isotopic partitioning between scallop shell calcite and seawater : Effect of shell growth rate. Geochimica et Cosmochimica Acta, 66, 1727-1737.

Patterson, W.P., Smith, G.R. and Lohmann, K.C. (1993) Continental paleothermometry and seasonality using the isotopic composition of aragonitic otoliths of freshwater fishes. Geophysical Monograph, 78, 191-202.

Peterson, C.H., Duncan, P.B., Summerson, H.C. and Safrit, G.W.Jr. (1983) A mark-recapture test of annual periodicity of internal growth band deposition in shells of hard clams, Mercenaria mercenaria, from a population along the southeastern United States. Fish Bull U.S. 81, 765-779.

Reynolds, D.J., Scourse, J.D., Halloran, P.R., Nederbragt, A.J., Wanamaker, A.D., Butler, P.G., Richardson, C.A., Heinemeier, J., Eiríksson, J., Knudsen, K.L. and Hall, I.R. (2016) Annually resolved North Atlantic marine climate over the last millennium. Nature Communications, 7, 13502, doi: $10.1038 /$ ncomms 13502 . 
Sakai, S. (2006) Micromilling technique applied to foraminifer tests for sample preparation of geochemical analysis. Abstract International Symposium on Foraminifers, 29, 625-626.

Santos, S., Cardoso, J.F.M.F., Borges, V., Witbaard, R., Luttikhuizen, P.C. and van der Veer, H.W. (2012) Isotopic fractionation between seawater and the shell of Scrobicularia plana (Bivalvia) and its application for age validation. Marine Biology, 159, 601-611.

Sato, S. (1995) Spawning periodicity and shell microgrowth patterns of the venerid bivalve Phacosoma japonicum (Reeve). Veliger, 38, 61-72.

佐藤慎一 (2001) 成長一絶対成長. 池谷仙之 ・棚部一成 編「古生物の科学 3 , 古生物の生活史」: 46-65, 朝倉 書店.

佐藤慎一 (2010) 成長線. 日本古生物学会編「古生物学 事典第 2 版」: 288-289, 朝倉書店.

Schöne, B.R., Lega, J., Flessa, K.W., Goodwin, D.H. and Dettman, D.L. (2002) Reconstructing daily temperatures from growth rates of the intertidal bivalve mollusk Chione cortezi (northern Gulf of California, Mexico). Palaeogeography, Palaeoclimatology, Palaeoecology, 184, 131-146.

Schöne, B.R., Tanabe, K., Dettman, D.L. and Sato, S. (2003) Environmental controls on shell growth rates and $\delta^{18} \mathrm{O}$ of the shallow-marine bivalve mollusk Phacosoma japonicum in Japan. Marine Biology, 142, 473-485.

Schöne, B.R., Oshmann, W., Tanabe, K., Dettman, D.L., Fiebig, J., Houk, S.D. and Kanie, Y. (2004) Holocene seasonal environmental trends at Tokyo Bay, Japan, reconstructed from bivalve mollusk shells-implication for changes in the East Asian monsoon and latitudinal shifts of the Polar Front. Quaternary Science Reviews, 23, 1137-1150.

Schöne, B.R., Dunca, E., Fiebig, J. and Pfeiffer, M. (2005a) Mutvei's solution : an ideal agent for resolving microgrowth structures of biogenic carbonates. Palaeogeography, Palaeoclimatology, Palaeoecology, 228, 149-166.

Schöne, B.R., Fiebig, J., Pfeiffer, M., Gleh, R., Hickson, J., Johnson, A.L.A., Dreyer, W. and Oschmann, W. (2005b) Climate records from a bivalved Methuselah
(Arctica islandica, Mollusca ; Iceland). Palaeogeography, Palaeoclimatology, Palaeoecology, 228, 130148.

Surge, D. and Walker, K.J. (2006) Geochemical variation in microstructural shell layers of the southern quahog (Mercenaria campechiensis) : Implications for reconstructing seasonality. Palaeogeography, Palaeoclimatology, Palaeoecology, 237, 182-190.

Takesue, R.K. and van Geen, A. (2004) $\mathrm{Mg} / \mathrm{Ca}, \mathrm{Sr} /$ $\mathrm{Ca}$, and stable isotopes in modern and Holocene Protothaca ataminea shells from a northern Calfornia coastal upwelling region. Geochimica et Cosmochimica Acta, 68, 3845-3861.

Tanabe, K. (1988) Age and growth rate determinations of an intertidal bivalve, Phacosoma japonicum, using internal shell increments. Lethaia, 21, 231241.

Tanabe, K. and Oba, T. (1988) Latitudinal variation in shell growth patterns of Phacosoma japonicum (Bivalvia: Veneridae) from the Japanese coast. Marine Ecology Progress Series, 47, 75-82.

Thébault, J., Chauvaud, L., Clavier, J., Guarini, J., Dunbar, R.B., Fichez, R., Mucciaron, D.A. and Morize, E. (2007) Reconstruction of seasonal temperature variability in the tropical Pacific Ocean from the shell of the scallop, Comptopallium radula. Geochimica et Cosmochimica Acta, 71, 918-928.

Thorrold, S.R., Campana, S.E., Jones, C.M. and Swartet, P.K. (1997) Factors determining $\delta^{13} \mathrm{C}$ and $\delta^{18} \mathrm{O}$ fractionation in aragonitic otoliths of marine fish. Geochimica et Cosmochimica Acta, 61, 2909-2919.

Titschack, J., Zuschin, M. Spötl, C. and Baal, C. (2010) The giant oyster Hyotissa hyotis from the northern Red Sea as a decadal-scale archive for seasonal environmental fluctuations in coral reef habitats. Coral Reefs, 29, 1061-1075.

富岡直人 - 景山智波 - 佐藤優子 - 森田耕起 - 山畑秀矢 太田有香 ·畑山智史 · 眞田恭平 ·金 英熙 - 賈 笑冰 （2015）小珠山遺跡出土アサリの酸素・炭素安定同位 体比分析の基礎的研究. 半田山地理考古, no. 3, 91100.

Ullmann, C.V., Wiechert, U. and Korte, C. (2010) Oxygen isotope fluctuations in a modern North Sea oyster (Crassostrea gigas) compared with annual 
variations in seawater temperature : Implications for palaeoclimate studies. Chemical Geology, 277, 160-166.

Wanamaker, Jr. A.D., Kreutz, K.J., Borns, H.W., Introne, D.S., Feindel, S., Funder, S., Rawson, P.D. and Barber, B.J. (2007) Experimental determination of salinity, temperature, growth, and metabolic effects on shell isotope chemistry of Mytilus edulis collected from Maine and Greenland. Paleoceanography, 22, PA2217, doi:10.1029/2006PA001352.

Wanamaker, Jr. A.D., Heinemeier, J., Scourse, J.D., Richardson, C.A., Butler, P.G., Eiríksson, J. and Knudsen, K.L. (2008) Very long-lived mollusks confirm 17th century ad tephra based radiocarbon reservoir ages for North Icelandic shelf waters. Radiocarbon, 50, 399-412.

Wanamaker, Jr. A.D., Butler, P.G., Scourse, J.D., Heinemeier, J., Eiríksson, J., Knudsen, K.L. and Richardson, C.A. (2012) Surface changes in the North Atlantic meridional overturning circulation during the last millennium. Nature Communication, 3, 899, doi:10.1038/ncomms1901.

Watanabe, T. and Oba, T. (1999) Daily reconstruction of water temperature from oxygen isotopic ratios of a modern Tridacna shell using freezing microtome sampling technique. Journal of Geophysical Research, 104, 20667-20674.

Watanabe, T., Suzuki, A., Kawahata, H., Kan, H. and Ogawa, S. (2004) A 60-year isotopic record from a mid- Holocene fossil giant clam (Tridacna gigas) in the Ryukyu Islands : physiological and paleoclimatic implications. Palaeogeography, a Palaeoclimatology, Palaeoecology, 212, 343-354.
Weidman, C.R., Jones, G.A. and Lohmann, K. (1994) The long-lived mollusk Arctica islandica: A new paleoceanographic tool for the reconstruction of bottom temperatures for the continental shelves of the northern North Atlantic Ocean. Journal of Geophysical Research, 99, 18305-18314.

Welsh, K., Elliot, M., Tudhope, A., Ayling, B. and Chappell, J. (2011) Giant bivalves (Tridacna gigas) as recorders of ENSO variability. Earth and Planetary Science Letters, 307, 266-270.

Yamamoto, N., Sakai, S. and Kitamura, A. (2009) Evaluation of the $\delta^{18} \mathrm{O}$ value of the submarine cavernicolous micro-bivalve Carditella iejimensis as a proxy for palaeotemperature. Paleontological Research, 13, 279-284.

Yamamoto, N., Kitamura, A., Irino, T., Kase, T. and Ohashi, S. (2010) Climatic and hydrologic variability in the East China Sea during the last 7,000 years based on oxygen isotope records of the submarine cavernicolous micro-bivalve Carditella iejimensis. Global and Planetary Change, 72, 131-140.

Yamanashi, J., Takayanagi, H., Isaji, A., Asami, R. and Iryu, Y. (2016) Carbon and oxygen isotope records from Tridacna derasa shells : toward establishing a reliable proxy for sea surface environments. PLoS ONE 11, e0157659, doi:10.1371/journal.pone, 0157659

Yamaoka, Y., Kondo, Y. and Ito, H. (2016) Rate and pattern of shell growth of Glycymeris fulgurata and Glycymeris vestita (Bivalvia: Glycymerididae) in Tosa Bay as inferred from oxygen isotope analysis. Venus, 74, 61-69. 


\title{
Combined sclerochronological and oxygen isotope analyses of marine bivalve shells to examine high-resolution Holocene environmental changes
}

\begin{abstract}
Akihisa Kitamura*
The author reviews sclerochronological and oxygen isotope analysis of marine bivalve shells in order to examine high-resolution Holocene paleoceanographic changes. In that review, I

emphasize case studies from extremely longlived Arctica islandica, the shallow-water clam Phacosoma japonicum and submarine cavernicolous micro-bivalve Carditella iejimensis.
\end{abstract}

Keywords : marine bivalves, shells, sclerochronology, oxygen isotope, Holocene environmental changes

\footnotetext{
*Faculty of Science, Shizuoka University, 836 Oya, Suruga-ku, Shizuoka, 422-8529, Japan. E-mail : kitamura.akihisa@ shizuoka.ac.jp
} 